This is the accepted manuscript of the article, which has been published in Re-interpreting Cities with Play: Urban Semiotics and Gamification. In A. Brooks, E. Brooks, \& C. Sylla (Eds.), Interactivity, Game Creation, Design, Learning, and Innovation: ArtsIT 2018, DLI 2018 (pp. 276-285). ( Lecture Notes of the Institute for Computer Sciences, Social Informatics and Telecommunications Engineering; Vol. 256). Springer. https://doi.org/10.1007/978-3-030-06134-0_32

\title{
Re-interpreting cities with play Urban semiotics and gamification
}

\author{
Mattia Thibault ${ }^{1[0000-0002-3593-0350]}$ \\ ${ }^{1}$ Tampere University of Technology, Tampere 33720 FINLAND \\ mattia.thibault@tut.fi
}

\begin{abstract}
This paper aims to propose a semiotic perspective on how play can be used to change the citizens' perception of the city. The paper propose a meaning-centered understanding both of play activities (seen as resemantisations of the surrounding environment) and of urban spaces (seen as complex meaning-making machines) and attempts to show how the first ones can be used to re-interpret the second ones. Finally, a few examples such as parkour and flash mobs are analyses in order to test the efficacy of the approach.
\end{abstract}

Keywords: Urban play, gamification, semiotics, parkour, flash mobs.

\section{Urban play: an introduction}

Nowadays, the idea that cities shouldn't just be smart but also playable is gaining more and more recognition. This paper aims to propose a semiotic perspective for studying urban play in the wider frame of gamification, in order to deepen our understanding on how we can use play to affect the urban spaces and on what effects this might have on the citizens and their practices. In particular this paper focuses on outlining a meaning-centred approach to urban areas and to analyse how playful activities of reading and rewriting the city can influence the citizens' perception and interpretation of the urban environment.

Urban areas are not new to becoming playgrounds. Everybody has, at least once, played at "don't walk on the pavement lines", or encountered an hopscotch chalk drawing on a side-walk. But the city is also home of new forms of play, such as Pokémon Go, or new playful performances like flash-mobs.

Playing in the city, however, is not simply a matter of entertainment or having fun. Situationism was maybe the first movement to point it out, even if not in these terms. Gilles Ivain, in his Formoulaire pour un urbanisme nouveau [9], underlines how a situationsit approach might save the city from the modern "mental illness" of a banality driven by production and comfort. Places devoted to playfulness, argues Ivain, are able to influence strongly the citizens' behaviour and have a great force of attraction.

Nowadays the social importance of city-play is recognised again: it is seen, more and more, as an antidote to the anonymity of the urban environment. The inhabitants of cities feel increasingly powerless and disconnected in face of the changes brought by 
globalisation and by the ICT revolution. This is even more critical to vulnerable populations in a moment where the right to the city of lower classes, minorities and immigrants is often questioned. Urban play, on the other hand, reinforces the perception of "city ownership": it is an activity that requires immersion and lighthearted engagement and is able to build communities around a shared experience.

In Europe, for example, as around $75 \%$ of the EU population lives in urban areas, it is not surprising that the Union itself financed several projects that address the societal challenges related to cities by promoting the use of play and game-like activities - such as GIFT (exploring hybrid playful forms of virtual museum experiences) or City-Zen (using games to illustrate to citizens the benefits of a clean energy transition) - and recognises "Optimal and cost-effective use of behavioural games" as one of the main strategies in the forthcoming H2020 call "Visionary and integrated solutions to improve well-being and health in cities".

\section{$2 \quad$ Play and interpretation}

But, what is play? This is, of course, a tricky question. The debate on how to define play - and even if this endeavour is possible at all - is still open, and produces many arguments and counter-arguments. The most convincing perspectives, however, are those considering the concept of "play" more like an operational tool that an ontological definition. Wittgenstein's claim that there is nothing actually in common between all the activities that we label as play if not a family resemblance [25] means that any attempt of defining play is actually an attempt to $r e$-define it. It is an attempt to create a new concept while keeping the same label. Which is what Brian SuttonSmith states when he speaks of the rhetorics of play [18]. These are the different ways of conceptualising playfulness in order to use it either to explain or to control society around us.

In this paper, then, I will not attempt to propose a general definition of play, but only to define what is the rhetoric of play as semiosis [20]. The idea that play spurs from a different set of meaning has been advanced and described by several scholars, but its best conceptualization is to be found in the works of Juri Lotman. In the article "The place of art among other modelling systems" [12] which, as the title suggests, deals mainly with the cultural role of art, Lotman, exposes a restricted theory of playfulness. According to Lotman play involves the dynamic constant awareness of the possibility of alternate meanings to the one that is currently being perceived. These different meanings of the same element do not appear in static coexistence but "twinkle" while each interpretation makes up a separate synchronic slice, yet retains a memory of earlier meanings and the awareness of the possibility of future ones.

Basically, Lotman suggests that play involves a resemantisation of the world i.e. a systemic shift of its meaning. This resemantisation gives to the world a second, additional and fictional meaning, that the players perceive and interpret as such. The 
players, then, oscillate between two different systems of interpretation, between two different ways to make sense of the same physical reality. On the one hand, the players never give up completely their awareness of the "ordinary reality", but, on the other hand, they almost act as if the playful situation was real. From a semiotic standpoint, thus, the starting point of any playful activity is the systematic resemantisation of objects and actions, that translate the whole world (or better, a portion of it delimited by the borders of play) into the semiotic domain of play. This resemantisation, however, does not entail any serious confusion between the two domains, that are perfectly separated in the mind of the player.

Play's ability to resemantise our surroundings without the need to modify them, can be a rather important asset in any action that attempt to reappropriate alienated public spaces. The limits that citizens have in regard of their ability to act and change the urban spaces they inhabit, can be somewhat dismissed, if we act on our perception of the city and therefore our behaviour within it. We shall call this playful resemantisations of the urban spaces as acts of urban gamification.

The term "gamification" generally indicates the attempt of using game design elements and inducing a playful behaviour in order to boost user engagement and increase the efficacy of non-game activities, both digital and not. Gamification can be implemented in a vast range of activities, from promoting exercising to conditioning driving behaviours (the Swedish Speed Camera Lottery). The concept (born in the digital media industry between 2008 and 2010) has been applied especially to education and learning [17], business [24] and health [15].

Analytic approaches and theoretical frameworks are quite recent in the field and are articulated around a perspective focusing mainly on defining "game elements" and their efficacy [5] or on redefining gamification on the basis of the participant responses [8]. This second approach seems to be most efficient: as a recent study [7] points out, gamification's positive effects are greatly dependent on the context and on the final users of the activity.

\section{$3 \quad$ Cities as texts}

We have claimed that play can be a tool for making sense of the city in a way that is alternative to that of ordinary life. In order to understand how, however, we need to engage the semiotic properties of urban areas.

Already in 1980 Michel de Certeau in his L'invention du quotidien [3] proposed to consider the city as a textual form. This parallelism - metaphorically already implicit in the expression "urban fabric" - leads de Certeau to consider the city as a real texts, actualised (and transformed) by the practices of interaction and crossing of their inhabitants. The journey of the latter through the urban space, then, is nothing but an enunciation, by which the individuals take possession of the places and transforms them by introducing their own subjectivity. The city, then, is a text anything but fixed: 
it emerges as the result of practices of enunciation that, at the same time, actualise and deeply modify the urban spaces. In the same years, Marshall Berman, from another perspective, elaborated the idea of the city as a machine that produces meaning, a "multimedia presentation whose audience is the whole world" [2, p. 288].

The metaphor of urban space as a text, as well as that of the city as a producer of meaning, can be found, whit some distinctions, in urban semiotics. In one of the founding works of urban semiotics Ugo Volli [22] writes that from the semiotic point of view, an expressive reality that is renewed and continually redefines itself such as the city, is defined a discourse: a signifying practice which, however, at all times projected behind itself a text. The city is alive, it changes materially and in the sense that it projects; but in every time it is stable and legible as a book

The city, therefore, is not really a text, but rather acts as a text - as a text it can be read, but also approached, analysed and understood [23] [14].

The city, just like a text, is both an organic whole - that can be understood and labelled as a unique thing - and characterized by an irreducible structural heterogeneity - a city encompasses numerous texts of smaller scale (neighbourhoods, streets, buildings, signs, street furniture, graffiti ...). All these smaller texts are interconnected by their simultaneous presence within the city, which then becomes a web of meaningful elements connected to each other [22]. This is obviously an unstable and uncertain mingling, whose metamorphoses follow different times and rhythms, from the slow construction of new neighbourhoods to the quick work of street-writers and the ephemeral presence of advertising posters. This dual nature, of homogeneous text and of container of textualities of a smaller scale, is recognised by authors semioticians such as Lotman [11] and Cervelli and Sedda [4] and leads to a fundamental disappearance of a clear distinction between text and context. If, on the one hand, the elements of larger size can become the context for those, incorporated, of smaller size (a neighbourhood becomes the context of a building, a square that of a monument), the relationship between text and context is not limited to a simple relationship of incorporation, and therefore, on the other hand, it is possible that the objects of a smaller size, but with a greater symbolic efficacy, can become the context for larger-scale objects: "iconic" buildings and monuments are able to lessen the meaning of all that it is around them, creating a semiotic void that allows them to "shine". Urban areas, then, appear as a polilogical set to which we have to add also all the objects moving thought it: goods, trucks, cars and the inhabitants of the city themselves, which cross its spaces and are distributed in different parts of the city giving meaning to the metropolitan landscapes.

Text-cities, as already implied by de Certeau, are inevitably polyphonic texts, which elude any attempt of standardization by the political, economic or religious powers. The city-enunciated is the product of countless authors, eras and conceptions of urban spaces, to which correspond a great number of different strategies sometimes even conflicting - which meet, collide, mingle and overwrite each other in 
the city. The urban areas, then, become places whose elements are pervaded by an antagonistic tension: competing to obtain dominant positions (centrality, verticality, passages), attention (traffic) and prestige. This tension, however, is petrified in the buildings and streets of the city, which freeze them in a spatial arrangement. This incessant internal tension of urban spaces entails a constant transformation: the city is a variable text, alive, never identical to itself, a text that retains elements of its past (text as testis, Latin for witness) and interweaves them with those of the present (text as textus, Latin for fabric) in a set often heavily layered and ontologically complex [23].

This kaleidoscopic web of meaningful elements features also its own hierarchy: an ideological stratification that gives greater emphasis and meaning to the buildings of the political and religious power, to monuments and "landmarks" and, instead, relegates to a marginal role the communicative traces of most of the inhabitants, which can only count on their ephemeral presence, or recur to billboards, signs, graffiti.

This ideological stratification is accompanied by a historical one, which moves at different speeds: some elements of the city can last for thousands of years (the topography, the orientation of the street map), other for centuries (buildings, streets and monuments), other for years (signs and elements of street furniture) or weeks (posters and display cases), down to the momentary presence of the inhabitants themselves: every look at the city, then, essentially captures just a section of it.

If the city is certainly the product of a culture, on the other hand it is itself also a producer of culture. There is a city-enunciated, but also a city-enunciator, which produces meaning and tells about the society and the people who inhabit it.

Focusing on this specific characteristic of urban spaces, allows us to emphasize the ways in which they convey meaning, they communicate with those who inhabit them, walk them, live them. On the one hand, the meanings conveyed by a city profoundly influence the actions of their inhabitants, through obligations, prohibitions and directions. On the other hand, cities transform people into citizens: they make them urban and polite - words that come respectively from the Latin and Greek words for "city".

The city, then, can be considered as a complex communicating machine [14], object of discourses and analysis that interpret it providing identity and consistency, but, at the same time, it is itself the subject of discourses and an important producer of meaning and culture.

\section{Interpreting and re-interpreting urban spaces}

To live and move through the city means, first of all, to be able to read and to interpret it. The experiential aspect of the city becomes even more important if, as in our case, we want to focus on the relationship between playfulness and urban spaces: 
gamifying city spaces is, first of all, an operation of interpretation and reinterpretation. In this paragraph, we will focus briefly on how the city is read by its inhabitants and which mechanisms and actions are necessary to re-write it.

If we take in consideration the movement through the city, the constitutive heterogeneity of the city can be reduced to a basic axiological opposition between the continuation and interruption. The range of possibilities of movement and reading in the urban space, then, can be articulated four combinations: the continuation of the continuation (the fluid and uninterrupted movement), the interruption of the continuation (the insurmountable obstacle), the interruption of the interruption (temporary obstacle) and the continuation of the interruption (the impossibility of moving). From these combinations we can outline two classes of urban objects: the passage (the road, the entrance, the side-walk, the pedestrian crossing, subway, but also the car door) and the obstacle (the wall, enclosure, barrier, the closed gate, but also the passer-by, the policeman directing traffic and the traffic lights) [19]. These two classes of objects regulate the actions of whoever moves into the urban space through a series of possibilities and prohibitions.

On the one hand, passages and obstacles are, above all, signs of their possible uses - they convey the possibility or impossibility to cross them - while, on the other hand, they are also significant surfaces. The palaces of the city - their representing and communicating aesthetic surfaces - at the same time prevent and direct the gaze, according to projects of strategic manipulation, intended to steer and guide those who live and move through the city. These meaningful surfaces simultaneously block the view and become a surface on which to engrave messages, whether architectural (decorations), symbols (flags, logos), commercial (advertising), social (mortuaries), identity (commemorative plaques) or ideological (political posters, graffiti) [14]. The passages, on the other hand, direct, regulate and guide the reading of the urban text and therefore they become the place where citizens can make sense of it, through the selection and a reading order determined by the path.

A famous example of the different practices of city crossing is the work of Floch [6] outlining a typology of the users of the metro of Paris. As his work accurately highlights, the different ways of reading the city vary also according to what the "reader" selects as significant and meaningful within the "jungle of signs" that is the urban space.

To read a rich text such as a city, it is necessary to choose some saliences - which items are significant, and which are trivial - and then to draw isotopies between them, in order to give a unique and organic meaning to the heterogeneous whole in which these diverse elements are immersed. Selecting the saliences, however, is not enough to be able to move consciously within the city. If it is true that in a social environment everything becomes a sign of its possible use, on the other hand, many objects are used differently by different individuals or at different times. Some objects may even be "reinvented" through practices contradictory of their constituent strategic purpose. 
We should talk, then, of possible uses, in the plural form, thus implying the need for a second operation of selection and interpretation. The selection of a specific use between many possibilities is guided by a "urban semiotic competence" [22]: the ability to correctly interpret what the city tells us. This competence is rather pragmatic, as it will guide the inhabitants in their tasks for experiencing the city. The city itself can hinder or facilitate the use of this competence in virtue of its legibility the urban characteristic of assisting people in creating their mental maps and fostering wayfinding [13], which is nonetheless that the exercise of the urban semiotic competence.

The two classes of urban object that we discussed above, obstacles and passages, are products and objects of writing practices. Tracing a path, whether physically (building a bridge, a road, a tunnel), whether as a strategic choice to move through the city - including the choice to leave the track (climbing a fence, crossing the street where forbidden, ignoring a traffic light) - are all acts of writing.

It is writing also any act on and with surfaces: building, affixing, smearing, demolishing, uprooting, colouring the objects of the city. "Writing the city" assumes often a character of rewriting, of superimposing new writing to an existing text. Writing the city means adding layers of meaning, removing and filling gaps, rectifying what already exists in an environment that is then continuously modified. It is, therefore, a form of bricolage that re-works already existing elements and materials. The city, in a nutshell, is formed by a material substrate produced by the superposition of multiple inscriptions which, in turn, become the substrate and support of new writings, whether they are strategic or simply the traces of the human activities that take place in the urban space.

We can distinguish two polarities of city-writing: one close to the idea of the palimpsest (a medieval manuscript from which the writing has been scraped off so that the page could be reused for another document), involving the removal, at least partial, of the pre-existing substrate and the construction of something new, and one characterized by a kind of maquillage in the name of recovery, based on the transformation or resemantisation of existing urban objects. This second, more common, form of rewriting is exercised both by the power - for example with regard to the transformation of a convent in a hospital or in an ancient palace into a town hall - and by peripheral social actors - which occupy buildings, become squatters, camp in parks, write on the walls, and so on. These rewritings, even when with practical purposes, cannot be regarded as exclusively functional: instead, they always have a highly communicative character. On the one hand, they affect the general meaning of the object that is resemantised, and, on the other hand, they become a way for individuals or for social political or religious groups, to engrave themselves within the city-text, to leave a trace, to represent their existence within the universe that the city represents. 


\section{$5 \quad$ Ludicisation and playable cities}

We have claimed that cities are also a mean through which a culture represents itself and its own understanding of the universe. It is not surprising, then, if urban spaces are one of the areas touched by the ludicisation of culture - the cultural trend that sees games and play occupying a more and more central place in our society.

The city, then, becomes a playground, host of playful activities and interactions that escape from the places traditionally devoted to them. The very enunciation of these cities - the way we live them, cross them, interact with them - is becoming more and more playful. Urban practices that used to be absolutely "serious" are now reformulated or modified in order to follow this cultural change. These activities generally take the form of pervasive play practices, as they involve a widening of the boundaries (spatial, temporal and social) of the play activity, which will then involve large portions of public space, moments not institutionally devoted to play and unsuspecting passers-by [16].

The choices that lie behind the use of strategies of urban gamification may vary. Some of them are bottom-up actions fuelled by the desire of (re)appropriating public spaces or to send a political message, while others are merely marketing techniques put in place by fashion-following companies. What all they all have in common, however, is the desire to rewrite the city, to reshape it, to engrave oneself in it, to renew it by resorting to the energy and the ability to motivate people that emanates from play. Let's engage a few examples.

\subsection{Flash mobs}

Flash mobs are probably one of the most widespread practices of urban play. They take place at the hearth of the city, in squares, streets or train stations and involve the sudden gathering of a crowd of people executing an unusual performance with a playful flavour. Flash mobs invade the space of traditional events: they have the same purposes and settings of protest marches, sit-ins, and fairs and they often replace them [21]. We have flash mobs used for political protest, and others promoting moments of sociability (e.g. the "dinners in white"). Flash mobs that have commercial purposes and advertise some product, while others are purely recreational (as are "zombie walks"). They all work in the same way: during the performance, the spaces of the city are transformed in improvised stages for shows that involve masking, carnivalesque features, and surrealisms.

Flash mobs, then, are a semiotic device aiming at acting on the border between everyday reality and play: viewers of a flash mob become players without their knowledge. The communicative effectiveness of these practices is based on this interpretative disorientation: the temporary inability to distinguish between semiotic domains. Flash mobs play with the status of playfulness, they omit the message "this is play" [1] and entrust it to an implicit metacommunication: passers-by have to 
activate their competence in the semiotic domain of play in order to be able to correctly interpret the scene unfolding before their eyes.

\subsection{Parkour}

Another interesting case of playful rewriting of urban spaces, this time concerning the reinterpretation of its obstacles, is that of parkour. Parkour was born in the degraded suburbs of Paris, and in particular in Evry. This practice started as a form of rebellion against the power and its writings of the city. Evry, as many other French suburbs, is an artificial city inaugurated in the 1970s for hosting immigrants. It was the product of a top-down urbanist ideology that did imagine the city as a space completely regulated by the power, at whose centre, functional and symbolic, stand the prefecture [10]. This project, therefore, failed spectacularly at constructing that polyphonic and plural character that we have identified as a constituent of a city able to transform its inhabitants into citizens.

The urban writing in Evry, unsurprisingly, was perceived by its own inhabitants as an imposition, a vexation. Some of them, however, reacted in an unusual way: with a practice of rewriting that had a strong playful component: parkour.

Parkour is an acrobatic alternative to the traditional ways of crossing the city spaces, those prescribed by the power. It defines a new way of moving within the city $[10]$ and, therefore, a new way of enunciating it and making it meaningful. Parkour is characterized, on the one hand, by speed (symbolic fruit of the conflicting relationship between the traceurs - the people which traces these new paths - and the power, which often results in them escaping from of the police) and on the other by an unusual way to relate to the obstacle. The obstacle is an element used to coerce, and it has a dual nature: symbolic and concrete - in indicates a route and it prescribes it. The traceurs, however, refuse the path imposed by the obstacle - which in Evry often prevents a fluid movement in space, forcing its inhabitants to long zigzagging - and replace it with an alternative route, which overcomes the obstacles with stunt jumps, transforming them into an opportunity to test physical and mental abilities.

Parkour has clearly a playful component: it can be interpreted as an attempt to resemantise in a playful way the urban space, it is manifested as a desire to turn the entire city into a huge playground, where all the elements of urban architecture are resemantised and re-functionalised in for urban entertainment, stripped of their practical functionality and covered with a playful functionality. This is not because traceurs are particularly playful, but because play appears as the only alternative to the interpretation of the city imposed by the power.

\subsection{Other}

There are of course many other examples that will have to be taken into consideration and that here we can only mention. The fact that the practice of city rewriting par excellence, graffiti, is often contained by video games (see the work of famous French 
street-artist Invader) and, more recently, by internet memes, is rather interesting. Some activities have a clearer aim at reappropriation, as Park(ing) day, a civil bottomup festivity in which people from around the World rent parking spots but, instead of parking their car, they unroll some clods of grass, position some plants and create a small, green, park instead. There are coordinated projects such as Fun Theory from Volkswagen, that employ a more "classic" take on gamification trying to devise ways of influencing people's behaviour through play, such as Piano Stairs, The World's deepest bin or the Speed camera lottery. Finally, platforms such as Playable cities promote projects that make high use of technology in order to rewrite city experiences, for example recording the shadows of passers-by and projecting them a few minutes late (Shadowing) or allowing citizens to exchange texts with streetfurniture (Hello Lamp post).

\section{Conclusions}

In this paper we have seen how the city, a semiotic machine stupendously complex, as well as its innovative digital representations, is increasingly subject of playful resemantisations. Play is able to infiltrate several contexts and spaces, and propose new meanings, new constraints, new strategies and new motivations.

This sort of meaning-centred approach to urban areas, can be rather useful to conceptualise the types of actions that can be undertaken in order to use play and to describe how they can influence the readings and interpretations of said spaces. Its descriptive capability, however, does not immediately translate in a prescriptive capability. In others words, if it helps us understand how urban gamification works, it is not enough to help us design activities of urban gamification, nor to assess them.

\section{Acknowledgements}

This project has received funding from the European Union's Horizon 2020 research and innovation programme under the Marie Sklodowska-Curie grant agreement No 793835 .

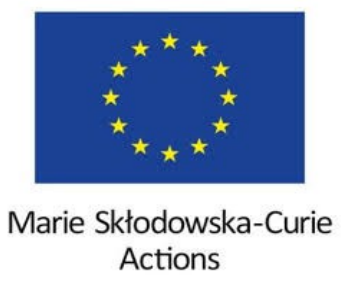

\section{References}

[1] Bateson, G., A theory of play and fantasy. Psychiatric research reports. 1955.

[2] Berman, M., All that is solid melts in the air. The experience of modernity. Simon and, New York, 1982.

[3] Certeau, M. De, L'invention du quotidien, 1. Arts de faire, Union générale d'éditions, Paris, 1980. 
[4] Cervelli P. and F. Sedda "Zone, frontiere, confini: la città come spazio culturale", in Marrone G. and I. Pezzini (eds.), Senso e metropoli. Per una semiotica posturbana, Meltemi, Roma, 2006, pp. 171-192.

[5] S. Deterding, R. Kahled, L. E. Nacke and D. Dixon, "Gamification: Toward a Definition" in CHI 2011, May 7-12, 2011, Vancouver.

[6] Floch, J.M., Sémiotique, marketing et communication : Sous les signes, les stratégies, PUF, Paris, 1990.

[7] J. Hamari, J. Koivisto and H. Sarsa "Does gamification work? a literature review of empirical studies on gamification" in 2014 47th Hawaii International Conference on System Sciences, 2014, pp. 3025-3034.

[8] J. Huotari and K. Hamari "A definition for gamification: anchoring gamification in the service marketing literature”, Electronic Markets 27(1), 2015, pp. 21-31.

[9] G. Ivain, "Formoulaire pour un urbanisme nouveau", Internationale situattioniste 1, Bulletrin céntral, Paris, 1958.

[10] M. Leone, "Le Parkour sémiotique. Pratiche urbane di invenzione della naturalità", in Bonadei R. (ed.), NaturaleArtificiale. Il palinsesto urbano,: Lubrina Bergamo, 2009.

[11] J. M. Lotman, "L'architettura nel contesto della cultura", in S. Burini (ed.) Il girotondo delle muse. Saggi sulla semiotica delle arti e della rappresentazione, Moretti and Vitali Editori, Bergamo, 1998.

[12] J. M. Lotman, "The place of art among other modelling systems" Sign Systems Studies 39(2/4) 2011, pp. 251-270.

[13] Lynch, K., The Image of the City, MIT press Cambridge, 1960.

[14] Mastroianni, R, Writing the city. I Saggi di Lexia, Aracne, Rome, 2013.

[15] McGonigal, J., Reality Is Broken: Why Games Make Us Better and How They Can Change the World, Penguin Books, London, 2011.

[16] Montola, M., Stenros, J. and A. Waern, Pervasive Games. Theory and Design, Morgan Kaufmann Game Design Books, San Francisco, 2009.

[17] Salen, K., The Ecology of Games: Connecting Youth, Games, and Learning, MIT press, Cambridge, 2007.

[18] Sutton-Smith, B., The ambiguity of play, Harvard University Press, Cambridge, 1997

[19] Thibault M. (ed.), Gamification Urbana: Letture e Riscritture ludiche degli spazi cittadini, I Saggi di Lexia, Aracne, Rome, 2016.

[20] Thibault M., The meaning of play. a theory of playfulness, toys and games as cultural semiotic devices. Doctoral dissertation, University of Turin, Turin, 2017.

[21] F. Turco, "Flash mob: quando la performance diventa strumento di protesta", Lexia 1314, Aracne, Rome, 2012, pp. 305-319.

[22] Volli, U., Laboratorio di semiotica, Laterza, Bari-Roma, 2005.

[23] U. Volli, "Il testo della città — problemi metodologici e teorici", in M. Leone (ed.) Lexia 1-2, Aracne, Rome, 2008, pp. 9-12.

[24] Werbach K. and D. Hunter (2012) For the win, How Game Thinking Can Revolutionize Your Business, Wharton Digital Press, Philadelphia, 2012.

[25] Wittgenstein, L., Philosophical Investigations, E. Anscombe (trans.) Palgrave Macmillan: New York, 1953. 